\title{
Student Editorial Board for Volume 28
}

Student Editorial Board members are appointed by members of the Editorial Board to serve for at least 1 year. Student members independently review manuscripts, which are also sent to their sponsoring board members. Participation on the board provides students with experience in the review process and provides authors of manuscripts with additional feedback. The following students currently serve on the Editorial Board or have served on that board during the last year. We are grateful for the contribution that each one has made to Law and Human Behavior.

Meera Adya, Law-Psychology Program, University of Nebraska at Lincoln Lucy Arnot, Law-Psychology Program, University of Nebraska at Lincoln Michael Davis, Forensicare, Monash University

Eric P. Green, Department of Psychology, University of South Carolina Laura Kunard, Department of Psychology, University of Illinois at Chicago Lora M. Levett, Department of Psychology, Florida International University E. Kiernan McGorty, Law-Psychology Program, University of Nebraska at Lincoln Stephanie Mears, Department of Psychology, York University

Jessica R. Meyers, Department of Psychology, University of Virginia Monica Miller, Law-Psychology Program, University of Nebraska at Lincoln Robert Nemeth, Department of Psychology, University of Nebraska at Lincoln Candice L. Odgers, Department of Psychology, University of Virginia Tim Robicheaux, Law-Psychology Program, University of Nebraska at Lincoln Stephen J. Ross, Department of Psychological Sciences, Ball Stall University Erin Spiers, Argosy University

Ronald S. Truelove, Department of Psychological Sciences, Ball Stall University Ryan Winter, Law-Psychology Program, University of Nebraska at Lincoln Jacqueline K. Buffington-Vollum, Department of Psychology, Southern Methodist University

Laura Zimmerman, Criminal Justice Program, University of Texas at El Paso 